\title{
Enhancement of maternal lactation performance during prolonged lactation in the mouse by mouse GH and long-R3-IGF-I is linked to changes in mammary signaling and gene expression
}

\author{
Darryl L Hadsell ${ }^{1,2}$, Albert F Parlow ${ }^{3}$, Daniel Torres ${ }^{1}$, Jessy George ${ }^{\mathbf{1}}$ and Walter Olea ${ }^{1}$ \\ ${ }^{1}$ Department of Pediatrics, Baylor College of Medicine, USDA/ARS Children's Nutrition Research Center, Houston, Texas 77030, USA \\ ${ }^{2}$ Department of Molecular and Cellular Biology, Baylor College of Medicine, Houston, Texas 77030, USA \\ ${ }^{3}$ National Hormone Peptide Program, Harbor-UCLA Medical Center, Torrance, California 90509, USA \\ (Correspondence should be addressed to D L Hadsell; Email: dhadsell@bcm.tmc.edu)
}

\begin{abstract}
$\mathrm{GH}$, prolactin (PRL), and IGF-I stimulate lactation-related metabolic processes in mammary epithelial cells. However, the ability of these factors to stimulate milk production in animals varies depending on species and experimental variables. Previous work in our laboratory demonstrated that transgenic overexpression of des(1-3)IGF-I within the mammary glands of lactating mouse dams increased lactation capacity during prolonged lactation. This work also suggested that some of the effects of the overexpressed IGF-I may have been mediated through elevated concentrations of IGF-I or PRL in the systemic circulation. In the present study, murine GH and PRL, and a human IGF-I analog, long-R3-IGF-I (LR3), were administered as s.c. injections to compare their ability to enhance milk production, and alter mammary gland signaling and gene expression. Lactation capacity, as measured
\end{abstract}

by litter gain, was increased $(P<0 \cdot 05)$ by $\mathrm{GH}$, but not by PRL. LR 3 increased $(P<0 \cdot 05)$ mammary phospho-Akt and suppressors of cytokines signaling 3 (SOCS3) gene expression, and had a modest ability to increase $(P<0 \cdot 05)$ lactation capacity. GH both increased $(P<0.05)$ mammary SOCS1 expression and decreased $(P<0.05)$ mammary expression of tryptophan hydroxylase 1 , the rate-limiting enzyme in the synthesis of serotonin and a potential feedback inhibitor of lactation. These results suggest that while both GH and IGF-I stimulate milk production in the lactating mouse, the effect of GH may be additionally mediated through IGF-I-independent effects associated with repression of mammary serotonin synthesis.

Journal of Endocrinology (2008) 198, 61-70

\section{Introduction}

Insulin-like growth factor I (IGF-I) is known to mediate the actions of growth hormone $(\mathrm{GH})$ on peripheral tissues (Daughaday 2000). Prior studies on the mammary gland have suggested that some of the effects of GH on lactation might also be mediated through the actions of IGF-I (Dehoff et al. 1988, Prosser et al. 1990). In dairy cows, GH allows for milk production to maintain at higher levels for a longer period of time producing enhanced 'lactation persistence' (Bauman 1992, van Amburgh et al. 1997). This enhancement of lactation persistence has been suggested to be a valuable means of improving the well-being of dairy animals as well as enhancing profitability of dairy operations (van Amburgh et al. 1997). To take advantage of the power of mouse genetics, our laboratory has developed a litter cross-fostering approach that allows for studies on lactation persistence to be conducted using mice as a model for dairy animals (Hadsell et al. 2006, 2007). Following this approach, we demonstrated increased lactation persistence in a strain of transgenic mice (WAP-DES)

that overexpress des(1-3)human IGF-I (hIGF-I) within the mammary gland (Hadsell et al. 2005). Increased lactation capacity was evident as improved weight gain in cross-fostered litters and was associated with enhanced mammary gland development and wet weight. This increased performance was also associated with higher maternal lean body mass and elevated circulating concentrations of both des(1-3)hIGF-I and prolactin (PRL). Studies with IGF-I null mice have also provided data to suggest that some of the effects of IGF-I may be mediated through the regulation of PRL secretion by the pituitary (Stefaneanu et al. 1999). These observations support the hypothesis that some of the effects of GH and IGF-I on milk production during prolonged lactation may be due to indirect systemic effects mediated through PRL-dependent or other endocrine systems.

Data from a number of experimental models have shown that activation of the JAK/STAT pathway is a direct consequence of PRL or GH stimulation in COS cells expressing the receptors for these hormones (Gouilleux et al. 1995). Studies in our own laboratory have demonstrated that 
i.v. injection of recombinant murine PRL into the tail vein of a lactating mouse profoundly increases mammary STAT5 phosphorylation within minutes (Hadsell et al. 2007). On the other hand, IGF-I signals through several pathways including the phosphoinositide 3 (PI3)-kinase/Akt and JAK/STAT pathways (Dudek et al. 1997, Gual et al. 1998). Our own studies using i.v. injections of the long-R3 (LR3) analog of IGF-I, a form that has enhanced potency due to an inability to interact with IGF-binding proteins, demonstrated increased phosphorylation of both Akt and STAT5 within the mammary gland within minutes of injection (Lee et al. 2003, Hadsell et al. 2007). Although these observations suggest that both ligands have the capacity to activate shortterm signaling events within the mammary tissue of lactating mice, the effects of chronic treatment via s.c. injections have not been studied.

In the mammary gland, the ability of PRL to simulate milk synthesis may be limited by the induction of negative feedback inhibitors such as the suppressors of cytokines signaling (SOCS) genes (Sutherland et al. 2007). The most commonly studied members of this family include SOCS1, SOCS2, and SOCS3, and cytokine-inducible $\mathrm{SH} 2$ protein (CIS). In addition to potential effects on PRL signaling, the SOCS genes have also been found to play a feedbackinhibitory role in systems involving GH, IGF-I, and insulin (Ueki et al. 2004, Inaba et al. 2005, LeRoith \& Nissley 2005). There may also be other local feedback inhibition mechanisms within the gland that regulate milk production (Knight et al. 1998). Tryptophan hydroxylase 1 (TPH1) is one of the two isozymes, which catalyzes the rate-limiting step in serotonin biosynthesis (Fitzpatrick 1999). In the mammary gland, TPH1 was identified in a suppressive subtractive hybridization screen for genes dependent on PRL (Matsuda et al. 2004). Studies on the role of TPH1 in the mammary gland have led to the suggestion that serotonin produced through the actions of this enzyme in mammary secretory cells acts as a feedback inhibitor of lactation (Matsuda et al. 2004).

The primary goal of these studies was to compare the impact of LR3-IGF-I, recombinant murine PRL, or recombinant murine $\mathrm{GH}$ on milk production, and mammary gland development in the mouse during prolonged lactation. A second goal of the study was to determine whether the effects of these hormonal treatments on lactation capacity could be related to changes in mammary cell signaling, and mammary expression of the SOCS, CIS, and TPH1 genes.

\section{Materials and Methods}

\section{Experimental animals}

All animals were studied in accordance with procedures outlined in the NIH Guide to Care and Use of Experimental Animals. These experiments were approved by the Baylor College of Medicine Animal Care and Use Committee. Mouse dams from the CD-1 strain (Charles River Laboratories, Wilmington, MA,
USA) were the experimental unit in all studies. All dams were analyzed in their first lactation and none were concurrently pregnant during the course of these studies. Each dam received a cross-fostered litter of ten 1-day-old pups beginning on day 1 post partum to control for litter size. In addition, litter weights were equalized across all dams. Lactation was prolonged out to 37 days by cross-fostering 7-day-old pups onto each dam every 7 days as previously described (Hadsell et al. 2005, 2006). The relative maternal capacity for milk production was estimated using the weight gain of these independent cross-fostered litters during each of four 7-day periods, days 7-14, 14-21, 21-28, and 28-35. Beginning on day 14 post partum, the dams were given s.c. injections $(0 \cdot 1 \mathrm{ml})$ of saline or saline containing recombinant LR3-IGF-I (JRH Biosciences, Sigma-Aldrich, www.sigmaaldrich.com/) and recombinant murine GH (National Hormone and Pituitary Program, Torrance, CA, USA) or recombinant murine PRL (National Hormone and Pituitary Program). The number of dams per treatment group was 15, 15, and 10 for saline, LR3, and GH respectively. Injections were administered three times per day at 0800,1400 , and $2000 \mathrm{~h}$ respectively. The dose injected was 1.4 and $2.2 \mathrm{mg} / \mathrm{kg}$ body weight for LR3 and GH respectively. The ability of PRL to increase lactation capacity was tested in two separate experiments at a dose of either 1 or $4 \mathrm{mg} / \mathrm{kg}$ body weight respectively. The number of dams per treatment group was five in the first experiment and ten in the second one. Body composition of the dams was measured on day 36 by scanning each animal once with a PIXImus (Lunar Corp., Madison, WI, USA) dual X-ray absorptiometer as previously described (Nagy \& Clair 2000). Mammary glands were harvested on day 37 at $2-4 \mathrm{~h}$ following the last injection that was administered at $0800 \mathrm{~h}$. Sampling was timed among the all treatment groups to balance the interval between the last injection and the tissue collection. At the time of harvesting, wet weights were recorded on each of the two no. 4 mammary glands, also known as inguinal glands, located on either side of the ventral midline just slightly anterior to the rear legs. The glands were then either flash-frozen in liquid nitrogen and stored at $-80^{\circ} \mathrm{C}$ for further analysis or frozen in optimal cutting temperature (OCT)-embedding medium for cryosectioning. Plasma samples were prepared from trunk blood collected at the time of killing.

\section{Mammary gland development}

Epithelial content of the mammary tissue and alveolar luminal area was determined by segmentation analysis of images captured from hematoxylin- and eosin-stained mammary tissue sections. For each specimen, ten digital images were captured from randomly chosen fields using a Spot RT CCD (Diagnostic Instruments, Sterling Heights, MI, USA). Images were then coded to prevent investigator bias in the processing and analysis. For the measurement of percent epithelial area, the images manually processed using pixel selection tools within Adobe Photoshop 5.0 (Adobe Systems). This processing consisted of selection of the stromal elements 
within each image followed by pseudo-coloring to produce a binary image consisting of stromal and epithelial compartments. For the measurement of alveolar area, the major and minor axes of an ellipse, which would approximate each alveolus, were manually drawn onto the alveoli within each image. Images containing these drawn axes were then converted to binary images. The resulting binary images were then analyzed using Image Pro 5.1 (Media Cybernetics, Silver Spring, MD, USA). For epithelial area, the pixel area occupied by epithelium in each image was directly measured and expressed as a percentage of the entire image. For luminal area, the major and minor axes for each ellipse were measured in pixels and then converted to micrometers. Luminal areas were then calculated using the formula for an ellipse, $\pi(L / 2+$ $W / 2$ ), where $L$ is the major axis and $W$ is the minor axis.

\section{Hormone measurements}

The plasma concentrations of both human and murine IGF-I were measured using ELISA-based assays. The hIGF-I assay was a non-extraction IGF-I ELISA (Diagnostic Systems Laboratories, Inc., Webster, TX, USA) with a sensitivity of $20 \mathrm{ng} / \mathrm{ml}$ and an intra-assay coefficient of variation of 5-9\%. Murine IGF-I was measured using a rat/mouse-specific immunoenzymometric assay (Immunodiagnostic Systems, Inc., Fountain Hills, AZ, USA) with a sensitivity of $82 \mathrm{ng} / \mathrm{ml}$ and an intra-assay coefficient of variation of 5-7\%. Plasma progesterone was measured using a commercially available RIA (Diagnostic Systems Laboratory). This assay had a sensitivity of $0 \cdot 1 \mathrm{ng} / \mathrm{ml}$ using $25 \mu \mathrm{l}$ plasma, and reported intra- and inter-assay coefficients of variations of 5.6 and $3.3 \%$ respectively. For the analysis of plasma PRL and $\mathrm{GH}$, the samples were shipped on dry ice to the National Hormone and Pituitary Program. The intra-assay coefficients of variation for these assays were 4.2 and $4.4 \%$ respectively. The RIA immunoreagents are distributed to researchers on request by the National Institute of Diabetes and Digestive and Kidney Diseases, National Hormone and Pituitary Program.

\section{Western blotting}

Total tissue protein extracts of mammary tissue were prepared from $50 \mathrm{mg}$ tissue and western blotting was conducted as previously described (Hadsell et al. 2003). Briefly, blots were prepared using PROTRAN nitrocellulose (Schleicher \& Schuell, Keene, NH, USA). Detection was based on enhanced chemiluminescence using SuperSignal West Pico Chemiluminescent Substrate (Pierce, Rockford, IL, USA), an HRP-conjugated donkey anti-rabbit at a dilution of 1:2000 (Amersham Biosciences), and BioMax MR film (Kodak). Phospho-Akt was measured using an antibody $(1: 1000$ dilution) to phospho-Ser ${ }^{473}$ that reacts with all three Akt isoforms (Cell Signaling Technology, Beverly, MA, USA). Phospho-ERK1/2 was measured using an antibody (1:1000 dilution) that detects dual phosphorylation of $\mathrm{Thr}^{202}$ and $\mathrm{Tyr}^{204}$ (Cell Signaling Technology). Phosphorylation of STAT5 was detected using an antibody (1:1000 dilution) to phospho-Tyr ${ }^{694}$ and total STAT5 (Santa Cruz Biotechnology, Santa Cruz, CA, USA). Phosphorylation of STAT3 was analyzed using an antibody (1:1000 dilution) to phospho-Tyr ${ }^{705}$ and total STAT3 (Cell Signaling Technology). Total amounts of each of Akt1 and ERK1/2 were also measured by western blotting as previously described (Hadsell et al. 2001). Equality of protein loading ensured by running all samples on parallel gels that were subsequently stained with Coomassie blue. Densitometry data were acquired from the fluorograms using Scion Image (Scion Corporation, Frederick, MA, USA). All densitometry data were corrected for variations in loading using densitometry data obtained from the Coomassie-stained gels.

\section{Gene expression analysis}

RNA was isolated from a piece of the no. 4 mammary gland using Trizol reagent (Invitrogen). The isolated RNA was quantitated using a NanoDrop spectrophotometer. Taqman Gene Expression Assays (Applied Biosystems, Inc., Foster City, CA, USA) were used to quantitate mRNA for SOCS1 (Mm00782550_s1), SOCS2 (Mm00850544_g1), SOCS3 (Mm00545913_s1), CIS (Mm00515488_m1), and TPH1 (Mm00493794_ml) by quantitative RT-PCR. The 18S rRNA (X03205.1) was quantitated in each sample as a loading control. All of the Taqman assays used in this study were validated by the manufacturer over a six $\log$ dilution range and have efficiencies of $100 \pm 10 \%$. The intra-assay coefficients for variation for the assays ranged from $7 \cdot 1$ to $10 \cdot 7 \%$. Reverse transcription was performed on 10 ng RNA using Taqman reverse transcription reagents. The reaction mixture was $10 \mathrm{ng}$ RNA, $1 \times \mathrm{RT}$ buffer, $5.5 \mathrm{mM}$ magnesium chloride, $2.5 \mu \mathrm{M}$ random hexamers, 4 units RNase inhibitor, and 31.25 units MultiScribe reverse transcriptase. Reactions were incubated in an MJ Research PTC-200 Peltier Thermal Cycler (Bio-Rad Laboratories). The conditions were $10 \mathrm{~min}$ at $25^{\circ} \mathrm{C}, 1 \mathrm{~h}$ at $37^{\circ} \mathrm{C}$, and $5 \mathrm{~min}$ at $95^{\circ} \mathrm{C}$. The reactions were placed in a well of a MicroAmp optical 96-well reaction plate (Applied Biosystems) and mixed with a $40 \mu \mathrm{l}$ PCR mix containing $1 \times$ Taqman Universal PCR MasterMix and $1 \times$ Taqman Gene Expression Assay. Q-PCR was performed in a 7900 Fast Real-Time PCR System (Applied Biosystems). The reactions were incubated at $50{ }^{\circ} \mathrm{C}$ for $2 \mathrm{~min}$, then at $95^{\circ} \mathrm{C}$ for $10 \mathrm{~min}$. The reactions were then cycled 40 times at $95^{\circ} \mathrm{C}$ for $15 \mathrm{~s}$ and at $60^{\circ} \mathrm{C}$ for $1 \mathrm{~min} . \Delta C_{\mathrm{t}}$ was calculated from the $C_{\mathrm{t}}$ values of the gene of interest and the sample's $18 \mathrm{~S}$ rRNA content. Fold changes in the mRNA levels were calculated in relation to the saline controls as previously described (Livak \& Schmittgen 2001).

\section{Data analysis}

Litter weight gain data were analyzed in three ways. First, the repeated measures procedure of SPSS (version 12.01 for Windows; SPSS Inc, Chicago, IL, USA) was used to compare weekly weight gain of each cross-fostered litter. The model 
for this analysis used injection (LR3 versus $\mathrm{GH}$ versus saline) as the fixed variable, day post partum as a repeated measure within each dam, and litter gain during the pretreatment week as a covariate. Second, the same repeated measures procedure was used to compare the second derivative of weekly litter gain for each of the 3 weeks that the injections were administered. Finally, total weight gain of the cross-fostered litters for the entire 3-week period was compared using a one-way ANOVA. The model for this analysis used injection as a fixed variable and litter gain during the pretreatment week as a covariate. Maternal body weight data were analyzed using a repeated measures analysis. The model for this analysis used injection as a fixed variable, day post partum as a repeated measure within each dam, and maternal bodyweight during the pretreatment week as a covariate. Data for body composition, mammary weight, epithelial area, plasma IGF-I, plasma progesterone, western blotting, and real-time qRT-PCR were analyzed using a oneway ANOVA. Specific treatment group comparisons were then done using a one-way ANOVA by predefined contrasts between the saline-injected group and each of the other three treatment groups. All the data are presented as means \pm S.E.M. Differences were considered statistically significant at $P \leq 0 \cdot 05$.

\section{Results}

Our previous work on prolonged lactation in the mouse demonstrated that transgenic mice that overexpressed IGF-I within the mammary gland exhibited increased milk production during prolonged lactation (Hadsell et al. 2005). We also found that this enhanced lactation capacity was associated with a significant increase in the circulating concentrations of IGF-I and PRL, increased maternal body mass, and increased maternal lean tissue mass. To follow up on these results, we chose to compare the impact of exogenous LR3, GH, or PRL on milk production in lactating mouse dams during prolonged lactation. Based on the results of previous studies with rats and mice, we administered the hormones as s.c. injections three times per day (Noel \& Woodside 1993, Capuco et al. 1999). To confirm that our injection protocols provided an adequate dose and injection frequency to elevate circulating levels of these hormones, plasma samples were collected at either 4 or $8 \mathrm{~h}$ after the last injection depending on the experiment.

The first experiment to determine the ability of exogenous PRL to enhance lactation persistence used a dose that was shown to be biologically effective in previously published studies with both rats and mice (Noel \& Woodside 1993, Capuco et al. 1999). In this initial experiment, an s.c. daily dose of $1 \mathrm{mg} / \mathrm{kg}$ of murine PRL failed to increase lactation performance (Fig. 1A) and had no impact on maternal body weight (Fig. 1C). This dose of PRL also failed to increase maternal plasma PRL $(157 \pm 63$ and $94 \pm 38 \mathrm{ng} / \mathrm{ml}$ for salineand PRL-injected dams respectively). On the basis of this study, a second PRL experiment was conducted using a dose that was $4 \mathrm{mg} / \mathrm{kg}$ per day. In this second study, circulating

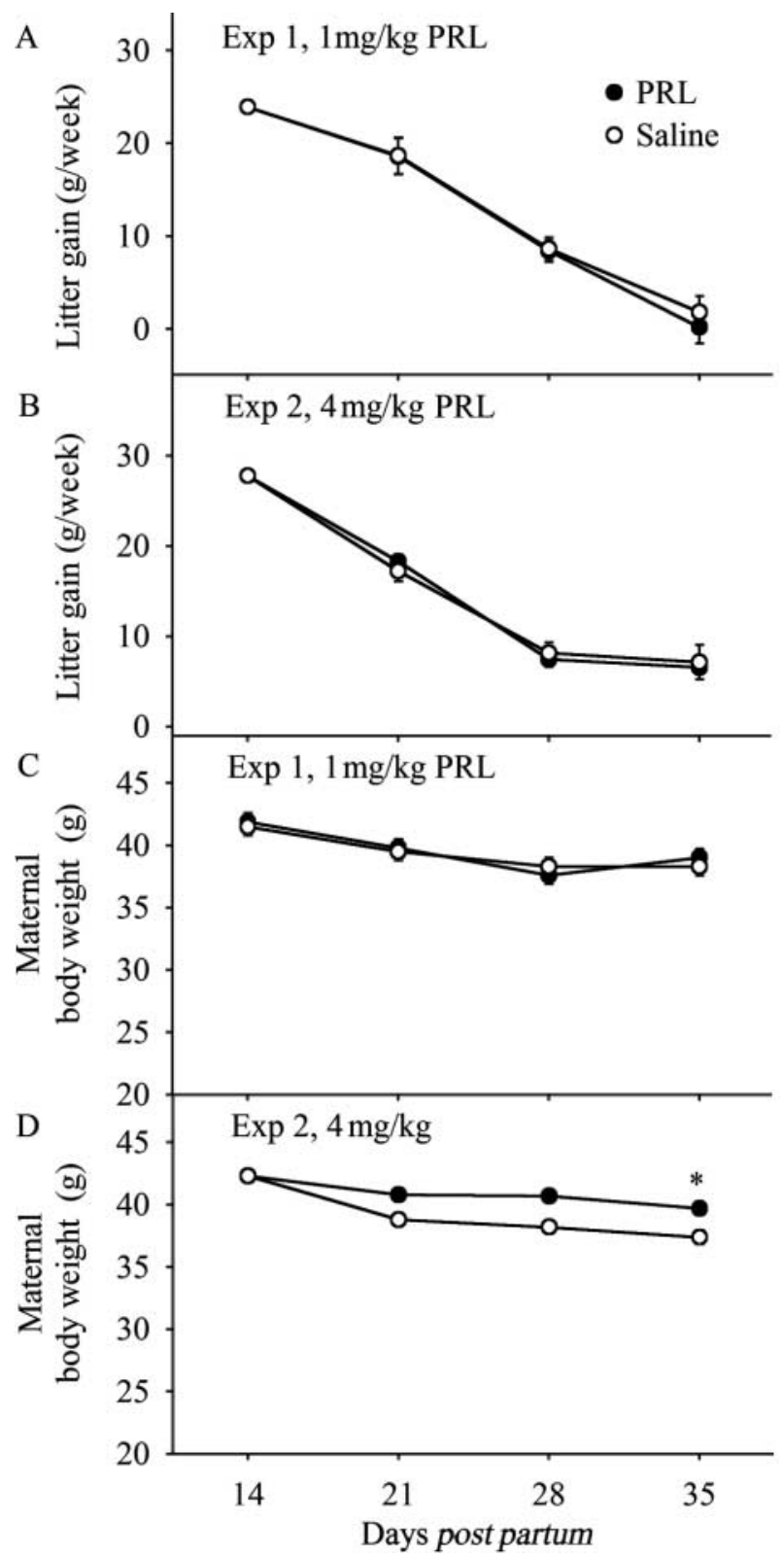

Figure 1 Exogenous administration of murine PRL has no impact on lactation capacity during prolonged lactation. The effect of exogenous recombinant murine PRL on (A and B) lactation capacity and $(C$ and $D)$ maternal body weight was measured in two separate experiments at a dose of either (A and C) 1 or (B and D) $4 \mathrm{mg} / \mathrm{kg}$ body weight/day. (A and B) Relative lactation capacity was estimated by comparing weekly weight gain of cross-fostered, weight-normalized, litters containing ten 7-day-old pups each among PRL- $(\mathbf{O})$ and saline-injected $(O)$ dams. (C and D) Maternal body was also compared between the two groups within each experiment. Each symbol represents the mean \pm S.E.M. for five dams each in $(A$ and $C)$ and ten dams each in $(B$ and $D)$. The asterisk indicates a statistically significant $(P \leq 0 \cdot 05)$ increase in maternal body weight. 
maternal PRL concentrations were elevated $(P<0 \cdot 05)$ in the PRL-injected group $(32 \pm 9$ and $1400 \pm 588 \mathrm{ng} / \mathrm{ml}$ in salineand PRL-injected dams respectively), but lactation capacity was still similar to that of saline-injected dams (Fig. 1B). Maternal body weight, however, was higher $(P<0 \cdot 05)$ in dams receiving PRL at $4 \mathrm{mg} / \mathrm{kg}$ per day than that of dams receiving saline (Fig. 1D). Interestingly, the high dose of PRL injected in the second experiment also decreased $(P<0 \cdot 05)$ maternal circulating concentrations of both progesterone and IGF-I. For progesterone, the concentrations were reduced in PRL-injected dams to $10 \%$ of that found in the salineinjected controls $(2 \pm 1$ and $21 \pm 4 \mathrm{ng} / \mathrm{ml}$ respectively). Maternal circulating IGF-I concentrations in PRL-injected dams were reduced to $77 \%$ of that found in the saline-injected group ( $399 \pm 45$ and $515 \pm 27 \mathrm{ng} / \mathrm{ml}$ respectively).

The ability of LR 3 to increase maternal lactation capacity in mice was tested using a dose similar to one that was previously shown to be biologically effective in mice (Stabnov et al. 2002). At a dose of $1.4 \mathrm{mg} / \mathrm{kg}$ per day, the concentration of hIGF-I in LR3-injected dams was $130 \pm 26 \mathrm{ng} / \mathrm{ml}$. There was no hIGF-I reactivity detectable in saline-injected dams. At this dose, LR3 had a modest capacity to increase weekly litter weight gain (Fig. 2A) and total litter gain $(P<0 \cdot 05)$ over the 3 -week treatment period (Fig. 2A inset). In addition, LR3 increased $(P<0 \cdot 05)$ maternal body weight (Fig. 2B). The maternal circulating concentrations of endogenous murine IGF-I were similar between saline- and LR3-injected dams $(515 \pm 27$ and $476 \pm 20 \mathrm{ng} / \mathrm{ml}$ respectively). In addition, the maternal circulating concentrations of progesterone were similar between saline- and LR3-injected dams $(21 \pm 4$ and $20 \pm 2 \mathrm{ng} / \mathrm{ml}$ respectively).

The ability of GH to increase maternal lactation capacity in mice was tested using a dose similar to one that was previously shown to be biologically effective in rats (Groesbeck et al. 1987). When administered at a dose of $2 \mathrm{mg} / \mathrm{kg}$ per day, GH increased $(P<0 \cdot 01)$ both lactation capacity (Fig. $2 \mathrm{~A})$ and maternal body weight (Fig. 2B). The effect of lactation capacity was observed both in terms of weekly litter gain (Fig. 2A) and total litter gain (Fig. 2A inset). The maternal circulating concentration of $\mathrm{GH}$ was significantly increased $(P<0.05)$ by $\mathrm{GH}$ injections $(5.5 \pm 1.7$ and $305 \pm 184 \mathrm{ng} / \mathrm{ml}$ in saline- and GH-injected dams respectively). The concentrations of endogenous murine IGF-I in circulation were also increased $(P<0 \cdot 05)$ in $\mathrm{GH}$-injected dams $(515 \pm 27$ and $729 \pm 41 \mathrm{ng} / \mathrm{ml}$ for saline- and GH-injected respectively). In addition, the wet weight of the no. 4 mammary glands was higher $(P<0.05)$ in $\mathrm{GH}-$ than saline-injected dams, and morphometric analysis of hematoxylin-eosin-stained mammary tissue sections demonstrated that alveolar lumenal area was also increased $(P<0 \cdot 05)$ in GH-injected dams (Fig. 2C). Neither LR3 nor PRL had a significant impact on mammary gland wet weight or morphology.

Because GH, LR3, and PRL all had the capacity to alter maternal body weight, DEXA analysis was used to determine whether maternal body composition was changed by these treatments as well. Maternal lean body mass (Lean) and total


Injection

Figure 2 Exogenous administration of $\mathrm{GH}$, and to a lesser degree LR3-IGF-I, increases lactation capacity during prolonged lactation. $(A$ and B) Lactation capacity was assessed in saline- $(\nabla)$ LR3- $(0)$ or $\mathrm{GH}$-injected $(\mathbf{O})$ dams by measuring the weekly or (A, inset) total weight gain of cross-fostered, weight-normalized, litters containing ten 7-day-old pups each. (C) Mammary gland development was assessed by comparing wet weight $(\boldsymbol{\square})$, percent epithelia $(\square)$, and lumen area $(\square)$ among mammary tissue harvested at 37 days post partum in saline-, LR3-, or GH-injected dam. Each symbol represents the mean \pm S.E.M. for 20,15, and 10 dams in the saline, $\mathrm{LR} 3$, and $\mathrm{GH}$ treatment groups respectively. The asterisks indicate a statistically significant $(P \leq 0 \cdot 05)$ increases relative to that observed for the saline-injected group.

bone area (Area) were higher $(P<0 \cdot 0001)$ in LR3- and $\mathrm{GH}$-treated dams than those in saline-injected dams (Table 1). Bone mineral content was higher $(P<0 \cdot 05)$ in LR3-treated dams than that in PRL-injected dams while percent body fat was lower $(P<0 \cdot 05)$ in GH-treated dams than that in salineinjected dams. 
Table 1 DEXA analysis of body composition in female mice treated with saline, prolactin, long-R3 (LR3)-insulin-like growth factor I, or growth hormone $(\mathrm{GH})$ during prolonged lactation

\begin{tabular}{|c|c|c|c|c|c|c|}
\hline & $\mathbf{B M D}^{\mathbf{a}}\left(\mathrm{g} / \mathrm{cm}^{2}\right)$ & $\mathbf{B M C}^{\mathrm{b}}(\mathrm{g})$ & $\operatorname{Area}^{\mathrm{C}}\left(\mathrm{cm}^{2}\right)$ & $\operatorname{Lean}^{\mathrm{d}}(\mathrm{g})$ & $\mathbf{F a t}^{\mathrm{e}}(\mathrm{g})$ & Fat $^{f}(\%)$ \\
\hline Sal & $0 \cdot 05 \pm 0 \cdot 001$ & $0 \cdot 48 \pm 0 \cdot 01^{*,+}$ & $10 \cdot 13 \pm 0 \cdot 22 *$ & $29 \cdot 14 \pm 0 \cdot 48^{*}$ & $2 \cdot 71 \pm 0 \cdot 17$ & $8.57 \pm 0.43 *$ \\
\hline $\mathrm{Prl}$ & $0 \cdot 05 \pm 0 \cdot 001$ & $0 \cdot 47 \pm 0 \cdot 01^{*}$ & $10 \cdot 06 \pm 0 \cdot 18^{*}$ & $29.83 \pm 0.55^{*}$ & $2 \cdot 98 \pm 0 \cdot 20$ & $8 \cdot 96 \pm 0 \cdot 50^{*}$ \\
\hline LR3 & $0 \cdot 05 \pm 0 \cdot 001$ & $0 \cdot 52 \pm 0 \cdot 01^{\dagger}$ & $11 \cdot 06 \pm 0 \cdot 18^{+}$ & $34 \cdot 58 \pm 0 \cdot 55^{\dagger}$ & $2 \cdot 77 \pm 0 \cdot 20$ & $7 \cdot 49 \pm 0 \cdot 50^{*,+}$ \\
\hline $\mathrm{GH}$ & $0 \cdot 05 \pm 0 \cdot 001$ & $0 \cdot 50 \pm 0 \cdot 02^{*,+}$ & $10 \cdot 86 \pm 0 \cdot 22^{+}$ & $34 \cdot 22 \pm 0.68^{+}$ & $2 \cdot 30 \pm 0 \cdot 24$ & $6 \cdot 59 \pm 0.61^{+}$ \\
\hline$P$ & $0 \cdot 8$ & $0 \cdot 026$ & $<0 \cdot 0001$ & $<0 \cdot 0001$ & $0 \cdot 2$ & $0 \cdot 013$ \\
\hline
\end{tabular}

${ }^{*}{ }^{+}$Means with different superscripts differ $(P<0 \cdot 05)$.

${ }^{a}$ Bone mineral density.

${ }^{\mathrm{b}}$ Total bone mineral content.

'Total bone area.

dLean tissue mass.

'Fat tissue mass.

fPercent body fat.

Having observed a differential ability of GH, LR3, and PRL to enhance milk production during prolonged lactation, we next wanted to determine whether these differences could be accounted for by potential differences in the ability of these factors to activate mammary signaling pathways or alter mammary gland gene expression. To measure the activation of signaling pathways that might be expected to be induced by IGF-I, western blotting was conducted for phospho-Akt and dual-phosphorylated ERK1/2 on mammary tissue samples that were collected at $4 \mathrm{~h}$ following the last s.c. injection of the 3-week treatment protocol (Fig. 3). This analysis demonstrated that phosphorylation of $\operatorname{Ser}^{473}$ on mammary Akt was higher $(P<0 \cdot 05)$ in LR3-injected dams than that in saline-injected dams (Fig. 3A). Total Akt was not altered by

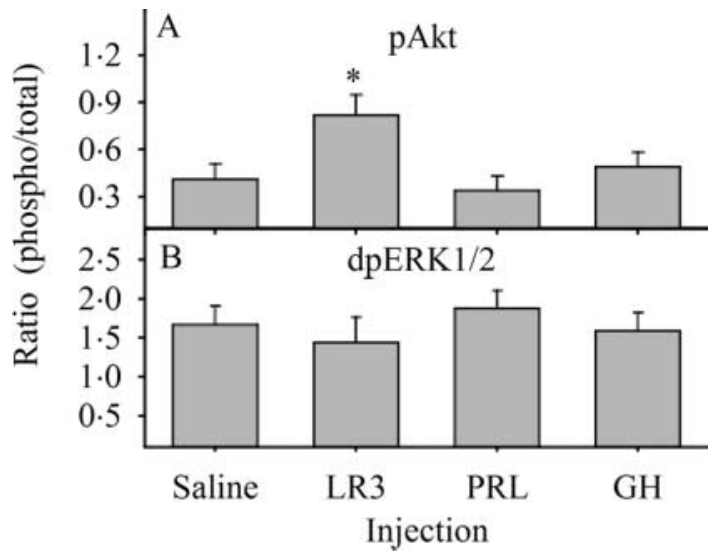

Figure 3 Exogenous administration of LR3, but not GH or PRL, increases phosphorylation of mammary Akt. Western blotting for phospho-Akt, dual phosphorylated ERK1/2, total Akt, and total ERK $1 / 2$ was conducted on extracts prepared from mammary tissue samples collected on day 37 post partum from lactating dams receiving s.c. injections of either saline, $L R 3, G H$, or PRL respectively. Tissue samples were collected at $2-4 \mathrm{~h}$ following the last injection. Densitometry was conducted to quantitatively compare the ratios of phosphorylated with total (A) Akt and (B) ERK1/2. Each bar represents the mean \pm s.E.M. for 20, 15, 10, and 10 dams in the saline, LR3, PRL, and $\mathrm{GH}$ treatment groups respectively. The asterisk indicates a statistically significant $(P \leq 0 \cdot 05)$ increase relative to that observed for the saline-injected group. any of the treatments (data not shown). Neither GH nor PRL had any effect on mammary Akt phosphorylation. Neither phospho-ERK1/2 nor total ERK1/2 was changed by any of the treatments (Fig. 3B).

To test for potential activation of pathways expected to be induced by PRL and GH, we used western blotting to measure phosphorylation of STAT5 and STAT3 (Fig. 4A and B). Phosphorylation of mammary STAT5 on $\mathrm{Tyr}^{694}$ was not affected by any of the treatments (Fig. 4A). Mammary abundance of total STAT5 was not affected by any of the treatments (data not shown). Phosphorylation of mammary STAT3 on $\operatorname{Tyr}^{705}$ was increased $(P<0 \cdot 05)$ in PRL-injected dams relative to that observed in saline-injected dams

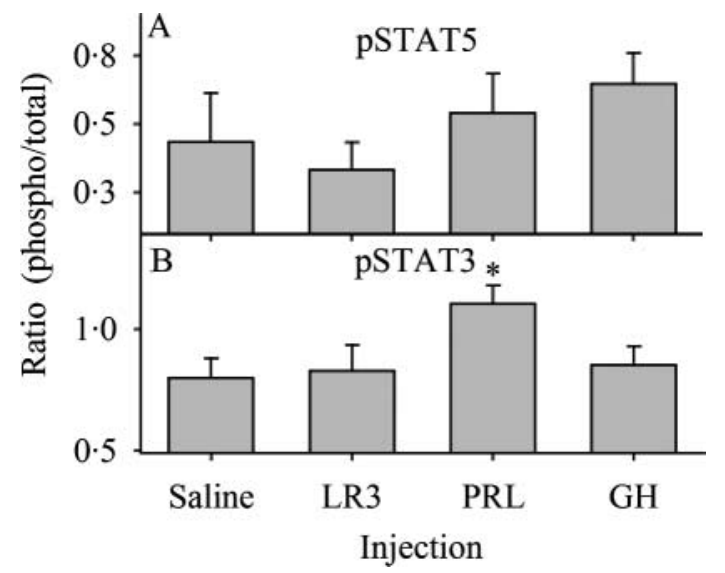

Figure 4 Exogenous administration of prolactin, but not GH or LR3, increases STAT3 phosphorylation within the mammary glands of mouse dams during prolonged lactation. Western blotting for phospho-STAT5, phospho-STAT3, total STAT5, and total STAT3 was conducted on extracts prepared from mammary tissue samples collected on day 37 post partum from lactating dams receiving s.c. injections of either saline, LR3, GH, or PRL respectively. Tissue samples were collected at $2-4 \mathrm{~h}$ following the last injection. Densitometry was conducted to quantitatively compare the levels of the ratios of phosphorylated with total (A) STAT5 and (B) STAT3. Each bar represents the mean \pm S.E.M. for 20, 15, 10, and 10 dams in the saline, $\mathrm{LR} 3, \mathrm{PRL}$, and $\mathrm{GH}$ treatment groups respectively. The asterisks indicate a statistically significant $(P \leq 0 \cdot 05)$ increases relative to that observed for the saline-injected group. 
(Fig. 4B). Abundance of total STAT3 in the mammary gland was not affected by any of the treatments (data not shown).

Because the expression of the SOCS genes can be induced in mammary tissue and other organs by cytokines and growth factors, we measured the mRNA levels of SOCS1, SOCS2, SOCS3, and CIS. We also measured the mRNA levels of $\mathrm{TPH} 1$, a gene that regulates the synthesis of serotonin, another potential feedback inhibitor of lactation. Real-time RT-PCR was used on total mammary RNA with probe and primer sets for SOCS1, SOCS2, SOCS3, CIS, and TPH1 (Fig. 5). Normalized threshold values (CT) were obtained by using primer probe sets for the murine 18S rRNA. Comparison of the CT values for the $18 \mathrm{~S}$ assay among the treatments demonstrated that this mRNA was not altered by the different hormonal treatments. Fold changes in the different genes were then calculated relative to the normalized CT for saline-injected dams (Fig. 5). The expression of

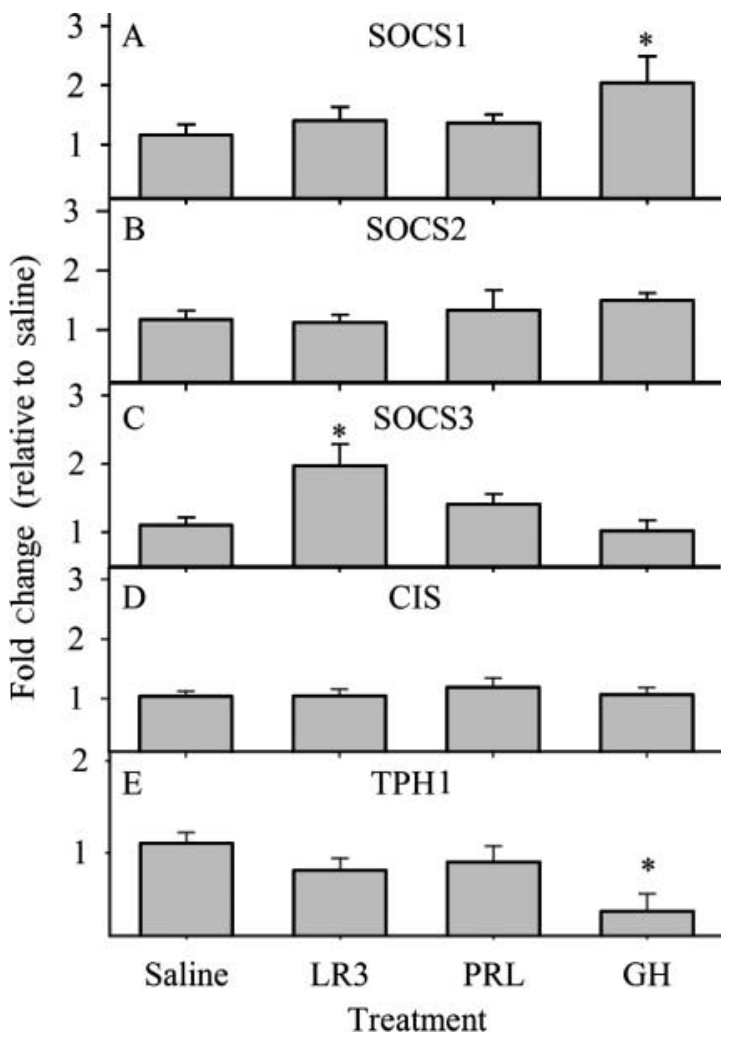

Figure 5 Exogenous administration of IGF-I, GH, and prolactin differentially affect mammary gland expression of SOCS genes and TPH1 during prolonged lactation. Total RNA from mammary tissue of lactating dams injected with either saline, LR3, GH, or prolactin was collected on day 37 post partum and analyzed for (A) SOCS1, (B) SOCS2, (C) SOCS3, (D) CIS, and (E) TPH1 by real-time RT-PCR. Expression data for each gene were calibrated to that for $18 \mathrm{~S}$ rRNA and then normalized relative to that observed for the saline-injected group to produce a fold change. Each bar represents the mean \pm S.E.M. for 20, 15, 10, and 10 dams in the saline, LR3, PRL, and GH respectively. The asterisks indicate a statistically significant $(P \leq 0 \cdot 05)$ difference relative to the saline-treated group.
SOCS1 was twofold higher $(P<0 \cdot 05)$ in mammary tissue of $\mathrm{GH}$-injected dams than that of saline-injected dams (Fig. 5A). The mRNA for SOCS3 was twofold higher $(P<0 \cdot 05)$ in mammary tissue of LR3-injected dams than that of salineinjected dams (Fig. 5C). In addition, the mRNA for TPH1 in mammary tissue of $\mathrm{GH}$-treated dams was reduced $(P<0 \cdot 05)$ to about $40 \%$ of that observed in saline-treated dams (Fig. 5D). None of the genes analyzed were perceptibly impacted by PRL in this study.

\section{Discussion}

These studies demonstrate for the first time that recombinant murine GH and LR3-IGF-I can increase maternal lactation capacity during prolonged lactation in the mouse. These data, combined with the observation that mammary gland wet weight and alveolar lumen area were both increased in GH-injected dams, support the conclusion that milk production was increased in response to $\mathrm{GH}$ and more modestly so in response to LR3. At this point, it is important to mention two caveats. The first is that litter weight gain could have been affected by changes in milk macronutrient content. In this regard, although we did not collect milk composition data, several previously published observations, including our own, suggest that the effects of GH and LR3 were due to changes in milk production, not in milk composition (Austin et al. 1991, Flint \& Gardner 1994, Hadsell et al. 2005). The second caveat is that mammary gland morphology and wet weight could have been influenced by the timing of tissue sampling relative to the last nursing event between each dam and its pups. While this is meritorious, published data on maternal behavior in rodents, including our own analysis of maternal behavior in mice during prolonged lactation, suggest that because sample collection took place during the day (1000-1200 h), the time period of separation between the dam and its litter would have been no longer than $20 \mathrm{~min}$ and was probably much shorter (Sodersten \& Eneroth 1984, Hoshino et al. 2006, Hadsell et al. 2007). These observations strongly support the conclusion that the effects of GH and LR3 were mediated through changes in milk production. Combined with the cell signaling and gene expression data, the results also suggest a novel mechanism for $\mathrm{GH}$ action in the mammary gland that involves direct effects through the TPH1 gene and indirect effects through the IGFI-mediated Akt activation. In addition, our results suggest that previously observed increases in lactation capacity in transgenic mice that overexpress des(1-3)hIGF-I were probably not mediated by increased circulating PRL (Hadsell et al. 2005). An important question that remains, however, is why these hormones are effective under some experimental conditions and in some species, but not others?

Numerous studies have examined the impact of PRL, GH, and IGF-I on milk production in lactating cows, goats, and rats respectively (Tucker 1974, Flint et al. 1984, 1994, Plaut et al. 1987, Davis et al. 1989, Prosser et al. 1990, Flint \& Gardner 
1994). Only a few studies have examined the impact of these hormones on lactation in the mouse (Nandi 1958a,b, Capuco et al. 1999, Hadsell et al. 2005). The data presented in this paper are the first to compare the effects of these three hormones on milk production, mammary cell signaling, and mammary gene expression during prolonged lactation in the mouse.

All the three hormones in this study had effects on maternal physiology, mammary cell signaling, or mammary gene expression. The PRL-injected dams exhibited increased body weight and altered circulating concentrations of both progesterone and IGF-I. The increased maternal body weight was probably a result of increased food intake since previous studies have demonstrated that PRL is orexigenic in rats (Byatt et al. 1993, Noel \& Woodside 1993, Woodside 2007). Surprisingly, neither the expression of SOCS3 nor the phosphorylation of STAT5 was increased in the mammary glands of PRL-injected dams. Our own previous work on PRL signaling has shown that the recombinant murine PRL used in the present study is capable of inducing mammary STAT5 phosphorylation when administered intravenously to lactating mice (Hadsell et al. 2007). In addition, others have demonstrated that exogenous $\mathrm{GH}$ and PRL increased the expression of SOCS3 in the mammary tissue of virgin mice (Le Provost et al. 2005). In lactating rats, however, SOCS gene expression was induced by exogenous PRL only after $48 \mathrm{~h}$ of separation from their litters, suggesting that milk removal impacts the regulation of SOCS gene expression by PRL or other cytokines (Tam et al. 2001). In addition, differences in the route of administration, the duration of treatment, and the timing of sample collection may have impacted our ability to detect changes in STAT5 phosphorylation and induction of SOCS gene expression. Regardless, an effect of PRL on milk production might still have been detected if it were present.

The effects of PRL on milk production in normal lactating rats as well as in dairy cows have been largely negative with the exception of one study on prolonged lactation (Flint et al. 1984). Both PRL and GH have been demonstrated to support lactogenesis in hypophysectomized mice (Nandi 1958a,b) and both factors also stimulate milk production in lactating rats that have been treated with anti-GH antiserum and bromocryptine (Flint \& Gardner 1994). In addition, GH or PRL can increase lactation capacity in conjunction with thyroxine in hypothyroid lactating mice (Capuco et al. 1999). In dairy cows and goats, $\mathrm{GH}$, but not PRL, has been shown to increase milk production (Plaut et al. 1987, Jacquemet \& Prigge 1990, van Amburgh et al. 1997). In addition, shortterm infusions of IGF-I have been found to increase milk synthesis in goats (Prosser et al. 1990). Our mouse data are consistent with the conclusion that milk production in normal lactating mice during prolonged lactation, as in cows and rats, is largely unresponsive to exogenous PRL. Our data are also consistent with the possibility that milk production may be more responsive to $\mathrm{GH}$ in mice than that in rats despite the fact that in both species PRL and GH elicit similar changes in maternal physiology that may not have been directly linked to milk production (Thatcher \& Tucker 1970).
The impact of exogenous GH and LR3 on maternal physiology in this study was evident in a number of the endpoints examined. Both GH and LR3 increased maternal body weight. However, unlike PRL, these increases probably occurred through a different mechanism since they were associated with alterations in body composition. The body weight and composition effects in LR3-injected dams were similar to those previously observed during prolonged lactation in the WAP-DES mice (Hadsell et al. 2005). The results are also consistent with the reported ability of IGF-I to improve nitrogen retention in female rats (Tomas et al. 1993). Along with the effects on body composition, however, the fact that milk production was increased in three independent mouse studies suggests that IGF-I, like GH, may be more effective at stimulating milk production in mice than in rats (Flint et al. 1992, 1994, Su \& Cheng 2004, Hadsell et al. 2005).

An important point to remember is that both LR3 and des(1-3)IGF-I are known to be more potent than wild-type, endogenous, IGF-I since they do not interact with IGFbinding proteins (Clemmons et al. 1992, Oh et al. 1993). From the standpoint of interactions with the type-I IGF receptor, des(1-3)IGF-I and wild-type IGF-I are equivalent, while LR3 has somewhat reduced affinity (Ballard et al. 1986, 1987, Bagley et al. 1989). The impact of this reduced affinity appears minimal from a biological standpoint since LR3 maintains greater potency than wild-type IGF-I in both in vitro and in vivo assays (Ballard et al. 1986, Tomas et al. 1993). Therefore, although endogenous IGF-I was elevated in the GH-injected dams, this elevation would be expected to have less of a biological effect than that found in the WAP-DES transgenic dams or the LR3-injected dams. Clearly, the LR3 impacted the gland since both Akt phosphorylation and SOCS3 gene expression were elevated. However, the milk production response to LR3 might have been greater if circulating concentrations were as high as those originally observed with the WAP-DES mice (Hadsell et al. 2005). In addition, the comparison of mammary cell signaling and gene expression between the LR3- and the GH-injected dams suggests the possibility that the impact of $\mathrm{GH}$ on milk production may be mediated through additional factors that are independent of IGF-I action. This point was evident from the fact that both SOCS1 and TPH1 gene expression were altered in mammary tissue of GH-injected mice, but not affected in LR3-injected dams. In addition, while SOCS3 might have also been expected to increase in mammary tissue of both the LR3- and GH-injected dams, it was only altered in response to LR3 (Adams et al. 1998, Yadav et al. 2005).

Among the most interesting aspects of the GH effects were the impact on mammary expression of the gene for TPH1. In the mammary gland, TPH1 controls the synthesis of serotonin, a factor that regulates the ability of PRL to support mammary gland development and milk synthesis (Matsuda et al. 2004). Targeted mutation of the TPH1 gene in mice inhibits mammary involution (Matsuda et al. 2004). The expression of TPH1 is inducible both by PRL and teat sealing, a treatment that inhibits activation of STAT 5 and causes mammary gland 
involution (Matsuda et al. 2004). The expression of TPH1 is also increased in the mammary tissue of lactating mice that are subjected to an interval nursing protocol that maintains lactation, but decreases the frequency of milk removal (Hadsell et al. unpublished data 2007). These observations, coupled with the fact that mammary expression of TPH1 was decreased in the GH-injected dams, suggest that some of the potential lactation-enhancing effects of GH may be mediated through decreased synthesis of mammary serotonin.

In summary, administration of exogenous GH, LR3-IGF-I, and PRL has significant effects on maternal physiology, mammary gland signaling, and mammary gene expression, yet only recombinant murine $\mathrm{GH}$ and LR3 were capable of enhancing lactation capacity in the litter cross-fostered mouse during prolonged lactation. A potential mechanism for the ability of GH to increase lactation capacity may lie in its ability to repress the expression of TPH1 within the mammary gland. This potential mechanism, and its regulation by the frequency of milk removal, will be the subject of future studies in both mice and dairy cows.

\section{Declaration of Interest}

The authors declare that there is no conflict of interest that would prejudice the impartiality of this scientific work.

\section{Funding}

This project was supported by funds from NIH DK52197 (D L H), the USDA cooperative agreement no. 58-6250-6001 (D L H), and CSREES no. 2007-35206-17831 (D L H).

\section{Acknowledgements}

The authors would like to thank Dr Sonali Jain for assistance with the animal experiments. They also thank Dr Robert J Collier for a critical review of the manuscript.

\section{References}

Adams TE, Hansen JA, Starr R, Nicola NA, Hilton DJ \& Billestrup N 1998 Growth hormone preferentially induces the rapid, transient expression of SOCS-3, a novel inhibitor of cytokine receptor signaling. Journal of Biological Chemistry 273 1285-1287.

van Amburgh ME, Galton DM, Bauman DE \& Everett RE 1997 Management and economics of extended calving intervals with use of bovine somatotropin. Livestock Production Science 50 15-28.

Austin CL, Schingoethe DJ, Casper DP \& Cleale RM 1991 Influence of bovine somatotropin and nutrition on production and composition of milk from dairy cows. Journal of Dairy Science 74 3920-3932.

Bagley CJ, May BL, Szabo L, McNamara PJ, Ross M, Francis GL, Ballard FJ \& Wallace JC 1989 A key functional role for the insulin-like growth factor 1 N-terminal pentapeptide. Biochemical Journal 259 665-671.

Ballard FJ, Read LC, Francis GL, Bagley CJ \& Wallace JC 1986 Binding properties and biological potencies of insulin-like growth factors in L6 myoblasts. Biochemical Journal 233 223-230.
Ballard FJ, Francis GL, Ross M, Bagley CJ, May B \& Wallace JC 1987 Natural and synthetic forms of insulin-like growth factor-1 (IGF-1) and the potent derivative, destripeptide IGF-1: biological activities and receptor binding. Biochemical and Biophysical Research Communications 149 398-404.

Bauman DE 1992 Bovine somatotropin: review of an emerging animal technology. Journal of Dairy Science 75 3432-3451.

Byatt JC, Staten NR, Salsgiver WJ, Kostelc JG \& Collier RJ 1993 Stimulation of food intake and weight gain in mature female rats by bovine prolactin and bovine growth hormone. American Journal of Physiology 264 E986-E992.

Capuco AV, Kahl S, Jack LJ, Bishop JO \& Wallace H 1999 Prolactin and growth hormone stimulation of lactation in mice requires thyroid hormones. Proceedings of the Society for Experimental Biology and Medicine 221 345-351.

Clemmons DR, Dehoff MH, Busby WH, Bayne ML \& Cascieri MA 1992 Competition for binding to insulin-like growth factor (IGF) binding protein-2, 3, 4, and 5 by IGFs and IGF analogs. Endocrinology 131 890-895.

Daughaday WH 2000 Growth hormone axis overview - somatomedin hypothesis. Pediatric Nephrology 14 537-540.

Davis SR, Gluckman PD, Hodgkinson SC, Farr VC, Breier BH \& Burleigh BD 1989 Comparison of the effects of administration of recombinant bovine growth hormone or N-met insulin-like growth factor-I to lactating goats. Journal of Endocrinology 123 33-39.

Dehoff MH, Elgin RG, Collier RJ \& Clemmons DR 1988 Both type I and II insulin-like growth factor receptor binding increase during lactogenesis in bovine mammary tissue. Endocrinology 122 2412-2417.

Dudek H, Datta SR, Franke TF, Birnbaum MJ, Yao R, Cooper GM, Segal RA, Kaplan DR \& Greenberg ME 1997 Regulation of neuronal survival by the serine-threonine protein kinase Akt. Science 275 661-664.

Fitzpatrick PF 1999 Tetrahydropterin-dependent amino acid hydroxylases. Annual Review of Biochemistry 68 355-381.

Flint DJ \& Gardner M 1994 Evidence that growth hormone stimulates milk synthesis by direct action on the mammary gland and that prolactin exerts effects on milk secretion by maintenance of mammary deoxyribonucleic acid content and tight junction status. Endocrinology 135 1119-1124.

Flint DJ, Clegg RA \& Knight CH 1984 Effects of prolactin, progesterone and ovariectomy on metabolic activities and insulin receptors in the mammary gland and adipose tissue during extended lactation in the rat. Journal of Endocrinology 102 231-236.

Flint DJ, Tonner E, Beattie J \& Panton D 1992 Investigation of the mechanism of action of growth hormone in stimulating lactation in the rat. Journal of Endocrinology 134 377-383.

Flint DJ, Tonner E, Beattie J \& Gardner M 1994 Several insulin-like growth factor-I analogues and complexes of insulin-like growth factors-I and -II with insulin-like growth factor-binding protein-3 fail to mimic the effect of growth hormone upon lactation in the rat. Journal of Endocrinology 140 211-216.

Gouilleux F, Pallard C, Dusanter-Fourt I, Wakao H, Haldosen LA, Norstedt G, Levy D \& Groner B 1995 Prolactin, growth hormone, erythropoietin and granulocyte-macrophage colony stimulating factor induce MGF-Stat5 DNA binding activity. EMBO Journal 14 2005-2013.

Groesbeck MD, Parlow AF \& Daughaday WH 1987 Stimulation of supranormal growth in prepubertal, adult plateaued, and hypophysectomized female rats by large doses of rat growth hormone: physiological effects and adverse consequences. Endocrinology 120 1963-1975.

Gual P, Baron V, Lequoy V \& Van Obberghen E 1998 Interaction of janus kinases JAK1 and JAK-2 with the insulin receptor and the insulin-like growth factor-1 receptor. Endocrinology 139 884-893.

Hadsell DL, Alexeenko T, Klemintidis Y, Torres D \& Lee AV 2001 Inability of overexpressed des(1-3)human insulin-like growth factor I (IGF-I) to inhibit forced mammary gland involution is associated with decreased expression of IGF signaling molecules. Endocrinology 142 1479-1488.

Hadsell DL, Bonnette S, George J, Torres D, Klementidis Y, Gao S, Haney PM, Summy-Long J, Soloff MS, Parlow AF et al. 2003 Diminished milk synthesis in upstream stimulatory factor 2 null mice is associated with decreased circulating oxytocin and decreased mammary gland expression of eukaryotic initiation factors 4E and 4G. Molecular Endocrinology 17 2251-2267. 
Hadsell DL, Torres DT, Lawrence NA, George J, Parlow AF, Lee AV \& Fiorotto ML 2005 Overexpression of des(1-3) insulin-like growth factor 1 in the mammary glands of transgenic mice delays the loss of milk production with prolonged lactation. Biology of Reproduction 73 1116-1125.

Hadsell DL, Torres D, George J, Capuco AV, Ellis SE \& Fiorotto ML 2006 Changes in secretory cell turnover, and mitochondrial oxidative damage in the mouse mammary gland during a single prolonged lactation cycle suggest the possibility of accelerated cellular aging. Experimental Gerontology 41 271-281.

Hadsell D, George J \& Torres D 2007 The declining phase of lactation: peripheral or central, programmed or pathological? Journal of Mammary Gland Biology and Neoplasia 6 705-713.

Hoshino K, Wakatsuki Y, Iigo M \& Shibata S 2006 Circadian Clock mutation in dams disrupts nursing behavior and growth of pups. Endocrinology 147 1916-1923.

Inaba $\mathrm{M}$, Saito $\mathrm{H}$, Fujimoto $\mathrm{M}$, Sumitani $\mathrm{S}$, Ohkawara $\mathrm{T}$, Tanaka $\mathrm{T}$, Kouhara H, Kasayama S, Kawase I, Kishimoto T et al. 2005 Suppressor of cytokine signaling 1 suppresses muscle differentiation through modulation of IGF-I receptor signal transduction. Biochemical and Biophysical Research Communications 328 953-961.

Jacquemet N \& Prigge EC 1990 Effect of prolactin infusion on lactation, glucose kinetics, and pancreatic hormones in lactating goats. Journal of Dairy Science 73 3433-3438.

Knight CH, Peaker M \& Wilde CJ 1998 Local control of mammary development and function. Reviews of Reproduction 3 104-112.

Lee AV, Taylor ST, Greenall J, Mills JD, Tonge DW, Zhang P, George J, Fiorotto ML \& Hadsell DL 2003 Rapid induction of IGF-IR signaling in normal and tumor tissue following intravenous injection of IGF-I in mice. Hormone Metabolic Research 35 651-655.

LeRoith D \& Nissley P 2005 Knock your SOCS off. Journal of Clinical Investigation 115 233-236.

Livak KJ \& Schmittgen TD 2001 Analysis of relative gene expression data using real-time quantitative PCR and the $2(-$ Delta Delta $\mathrm{C}(\mathrm{T}))$ method. Methods 25 402-408.

Matsuda M, Imaoka T, Vomachka AJ, Gudelsky GA, Hou Z, Mistry M, Bailey JP, Nieport KM, Walther DJ, Bader M et al. 2004 Serotonin regulates mammary gland development via an autocrine-paracrine loop. Developmental Cell 6 193-203.

Nagy TR \& Clair AL 2000 Precision and accuracy of dual-energy X-ray absorptiometry for determining in vivo body composition of mice. Obesity Research 8 392-398.

Nandi S 1958a Endocrine control of mammary gland development and function in the C3 11/HE Crgl mouse. Journal of National Cancer Institute 21 1039-1062.

Nandi S $1958 b$ Role of somatotropin in mammogenesis and lactogenesis in C3H/He CR GL mice. Science 128 772-774.

Noel MB \& Woodside B 1993 Effects of systemic and central prolactin injections on food intake, weight gain, and estrous cyclicity in female rats. Physiology and Behavior 54 151-154.

Oh Y, Muller HL, Lee DY, Fielder PJ \& Rosenfeld RG 1993 Characterization of the affinities of insulin-like growth factor (IGF)-binding proteins 1-4 for IGF-I, IGF-II, IGF-I/insulin hybrid, and IGF-I analogs. Endocrinology 132 1337-1344.
Plaut K, Bauman DE, Agergaard N \& Akers RM 1987 Effect of exogenous prolactin administration on lactational performance of dairy cows. Domestic Animal Endocrinology 4 279-290.

Prosser CG, Fleet IR, Corps AN, Froesch ER \& Heap RB 1990 Increase in milk secretion and mammary blood flow by intra-arterial infusion of insulin-like growth factor-I into the mammary gland of the goat. Journal of Endocrinology 126 437-443.

Le Provost F, Miyoshi K, Vilotte JL, Bierie B, Robinson GW \& Hennighausen L 2005 SOCS3 promotes apoptosis of mammary differentiated cells. Biochemical and Biophysical Research Communications 338 1696-1701.

Sodersten P \& Eneroth P 1984 Suckling and serum prolactin and LH concentrations in lactating rats. Journal of Endocrinology 102 251-256.

Stabnov L, Kasukawa Y, Guo R, Amaar Y, Wergedal JE, Baylink DJ \& Mohan S 2002 Effect of insulin-like growth factor-1 (IGF-1) plus alendronate on bone density during puberty in IGF-1-deficient MIDI mice. Bone 30 909-916.

Stefaneanu L, Powell-Braxton L, Won W, Chandrashekar V \& Bartke A 1999 Somatotroph and lactotroph changes in the adenohypophyses of mice with disrupted insulin-like growth factor I gene. Endocrinology 140 3881-3889.

Su HY \& Cheng WT 2004 Increased milk yield in transgenic mice expressing insulin-like growth factor 1. Animal Biotechnology 15 9-19.

Sutherland KD, Lindeman GJ \& Visvader JE 2007 Knocking off SOCS genes in the mammary gland. Cell Cycle 6 799-803.

Tam SP, Lau P, Djiane J, Hilton DJ \& Waters MJ 2001 Tissue-specific induction of SOCS gene expression by PRL. Endocrinology 142 5015-5026.

Thatcher WW \& Tucker HA 1970 Lactational performance of rats injected with oxytocin, cortisol-21-acetate, prolactin and growth hormone during prolonged lactation. Endocrinology 86 237-240.

Tomas FM, Knowles SE, Chandler CS, Francis GL, Owens PC \& Ballard FJ 1993 Anabolic effects of insulin-like growth factor-I (IGF-I) and an IGF-I variant in normal female rats. Journal of Endocrinology 137 413-421.

Tucker HA 1974 General Endocrinological Control of Lactation. New York: Academic Press pp 277-327.

Ueki K, Kondo T \& Kahn CR 2004 Suppressor of cytokine signaling 1 (SOCS-1) and SOCS-3 cause insulin resistance through inhibition of tyrosine phosphorylation of insulin receptor substrate proteins by discrete mechanisms. Molecular and Cellular Biology 24 5434-5446.

Woodside B 2007 Prolactin and the hyperphagia of lactation. Physiology and Behavior 91 375-382.

Yadav A, Kalita A, Dhillon S \& Banerjee K 2005 JAK/STAT3 pathway is involved in survival of neurons in response to insulin-like growth factor and negatively regulated by suppressor of cytokine signaling-3. Journal of Biological Chemistry 280 31830-31840.

Received in final form 19 March 2008

Accepted 8 April 2008

Made available online as an Accepted Preprint 8 April 2008 